\title{
Optimum design of nozzles' tribology systems of a diesel engine fuel injector with high values of rail pressure
}

\author{
V. Lazarev ${ }^{1}$, G. Lomakin ${ }^{1}$, E. Lazarev ${ }^{1}$, A. Mylnikov ${ }^{1}$ \\ \& G. Wachtmeister ${ }^{2}$ \\ ${ }^{1}$ South Ural State University, Russia \\ ${ }^{2}$ Technische Universität München, Germany
}

\begin{abstract}
One of the actual and important problems of modern motor engineering is the improvement of lifetime and ecological parameters with a decreasing of internal combustion engines' (ICE) exhaust gases toxicity. This problem should be solved by means of a detailed focus on the main tribosystem (needle - nozzle's body) of Common Rail (CR) fuel systems of diesel engines. One of the ways which allows one to influence the precision tribocontact's service life, quality of injection and, subsequently, the ecological parameters of diesel engines is the perfection of a nozzle's tribosystem design. The development of a new design of the nozzle, its perfection and experimental estimation of injection parameters with high rail pressures was the main aim and task of the investigation. The main parameters of the fuel injection were estimated with the help of the experimental nozzle under different rail pressures. The experimental nozzle from a hydrauliccontrolled system is used in the CR injector with electro-hydraulic controlling. As a result of the process visualization of fuel injection, the nature of the fuel streams development was established and injection rate characteristics were experimentally determined. The causes of the unstable injection and instability of characteristics under different pressures were determined and recommendations for improving the design of the nozzle with additional precision tribo-interface were presented.
\end{abstract}

Keywords: nozzle of fuel injector, tribosystems, precision tribocontact, injection rate characteristics, nozzle's design and service life. 


\section{Introduction}

The development of energy sources in transport engineering, like heat engines and diesel engines is characterized by further improvements in fuel efficiency and a reduction of toxicity in exhaust gases. To decrease the toxicity of exhaust gases, the duration of the fuel injection should be reduced by increasing the fuel pressure and perfection of a nozzle's tribosystems, which is realized in accumulating diesel injection systems, such as CR [1-3]. Fuel dispensing in such systems is carried out by means of electro-hydraulic devices placed in the fuel injector. In addition, the development of injection process and injection rate characteristics are determined by the features of hydrodynamic phenomena, caused by the movement of fuel in channels and by cavities.

At high values (more than $155 \mathrm{MPa}$ ) of rail pressures the instability of injection rate characteristics of the fuel injection was expected and the study of the causes of these phenomena leading to a deterioration of economic and environmental performance will allow to develop measures to eliminate them and to increase the technical level of diesel engines.

Injection rate characteristics and the structure of fuel streams for the investigating nozzle were estimated using technology of out-of-motor tests with an injection rate analyzer and high-pressure chamber, which are developed by specialists of the Institute of "Internal Combustion Engines" in the laboratory of München Technical University (München, Germany).

To implement high-pressure fuel injection, experimental nozzle was modified to increase the stiffness of the nozzle's body (fig. 1), which had previously been adapted to work with the $\mathrm{CR}$ injector. The nozzle has 8 injection holes with the diameter of $0.21 \mathrm{~mm}$ and the conic angle for hole axes of $120^{\circ}$.
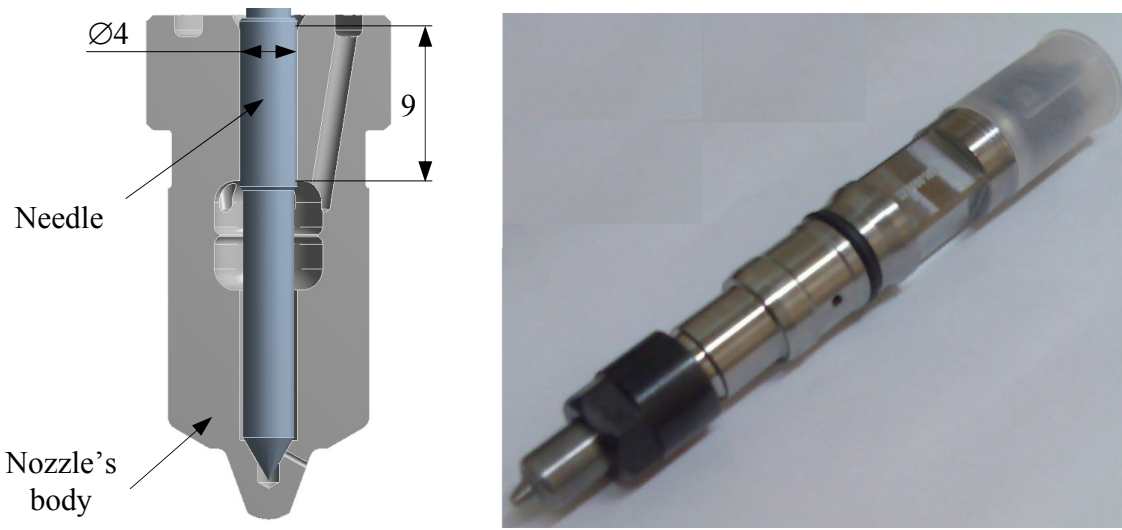

Figure 1: Design and adaptation of an experimental nozzle with guiding and sealing precision tribosystems for a CR injector. 


\section{Laboratory equipment for experimental investigations of the nozzle's injection and injection rate}

According to the subjects of investigation, the following research objectives were outlined:

- to estimate the opportunities for the use of the experimental nozzle with guiding and sealing precision tribosystems for a CR injector;

- to identify the injection rate characteristics of the experimental nozzle and their stability under different rail pressures;

- $\quad$ to receive the results of optical investigations with estimation of regular distribution of fuel into combustion chamber;

- to search the new nozzle's tribosystems design and ways of nozzle perfection considering the results of investigations of fuel injections at different rail pressures.

An injection rate analyzer (fig. 2(a)) is designed to determine the injection rate characteristics of the injection. It is a steel cylindrical container for nozzle installation connected with the thin-walled pipeline filled with diesel fuel, the length of which is approximately $10 \mathrm{~m}$ and the outer diameter of $10 \mathrm{~mm}$. The second end of the sensing line is connected with a pressure sensor, which has a union for feeding pressurized gas (air or nitrogen), that creates counter-pressure in the sensing line from 1 to $3 \mathrm{MPa}$. The injection rate per operation cycle is measured by injecting the diesel fuel under high pressure into the diesel fuel with a relatively low pressure (up to $3 \mathrm{MPa}$ ). The pressure wave formed in the measuring pipe is registered using the differential strain sensor and the data are used in calculating the injection rate by means of the well-known method developed by R. Bosch GmbH (Germany) [4, 5].

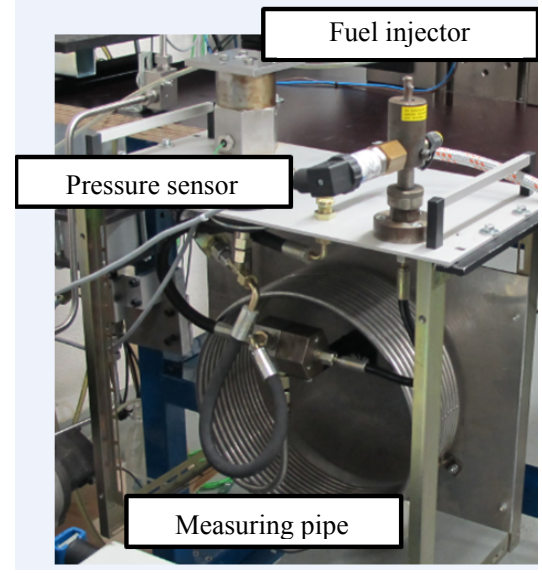

(a)

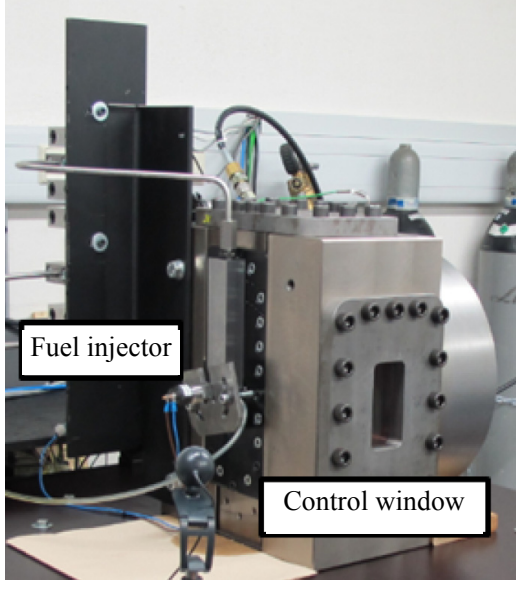

(b)

Figure 2: Injection rate analyzer (a) and high-pressure chamber (b) which were used for experimental investigations. 
The special high-pressure chamber (fig. 2(b)) is intended to simulate the condition of air in the diesel engine's cylinder and visualization of the condition and development of the fuel streams during the injection. It is a thick-walled stainless steel container equipped with a hole for the nozzle installation, and one front and two lateral windows to display the process of fuel injection with the help of a high-speed camera. The main purpose of the high-pressure chamber is to identify the following parameters of the fuel stream: angle of the spray, range and uniformity of fuel distribution in the fuel streams for the future adjustment with the shape and size of diesel engine's combustion chamber.

The main source of fuel pressure for an injection rate analyzer and a special high-pressure chamber is a special high-pressure fuel pump, driven by an electric motor.

\section{The analysis of received results}

Evaluations of the results of injection rate characteristics at different rail pressures are shown in fig. 3. The time of energizing was determined experimentally for various pressures of fuel injection and with account of requested fuel consumption per diesel engine's operation cycle. Relatively stable injection for an injector with investigated nozzle was found up to $155 \mathrm{MPa}$. Injection at pressures of more than $155 \mathrm{MPa}$ was found to be unstable and fuel consumption per operation cycle was increased and non-controlled. To prevent the unstable phase of injection, the time of energizing should be reduced but this value is limited by the electric device of the fuel injector.

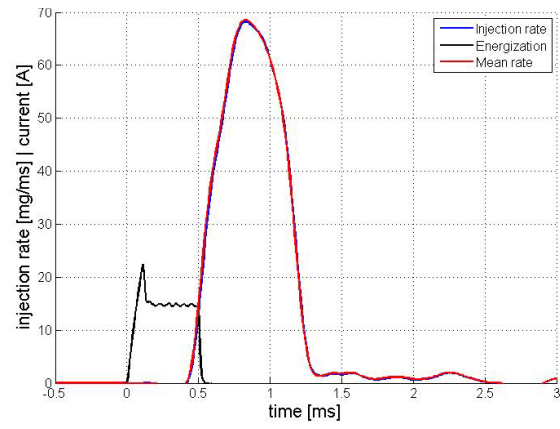

(a)

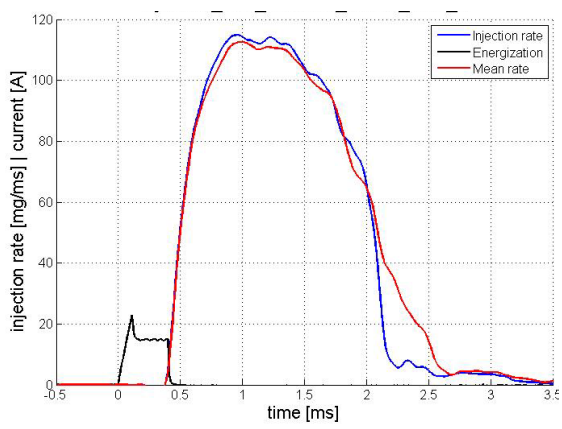

(b)

Figure 3: The time of energizing and rates of the fuel injection at different rail pressures: (a) $110 \mathrm{MPa}$; (b) $165 \mathrm{MPa}$.

The experimental results with an injection rate analyzer for the investigated nozzle are quite satisfactory results for a rail pressure up to $155 \mathrm{MPa}$. The increasing of the rail pressure to more than $155 \mathrm{MPa}$ is possible, but in this case it is necessary to modify the nozzle (to exclude the loss of moving ability of the 
needle) and to decrease the sum area of injection holes. These measures are considered as future steps of investigations.

Estimation of the uniformity of fuel distribution and range of fuel stream's penetration for the experimental nozzle, visual studies of injection process at different rail pressures were carried out with visualization of the injection processes in step by step mode. The example of received results (for maximal achieved stable rail pressure $-155 \mathrm{MPa}$ ) is shown in fig. 4 .

The slightly different intensity of fuel flows at relatively regular distribution and similar penetration of fuel were observed. It should be noted, that nonuniformity of the fuel streams in the combustion chamber is highly undesirable as it will not allow to get the requested fuel-air mixture with effective composition and will lead to the appearance of local (depending on the volume of combustion chamber) air coefficients and heat transfer factors from the operation gases in the combustion chamber walls. As a result, this situation will lead to reducing efficiency of the diesel engine's operation cycle. The appearance of non-uniformity distribution of injected fuel in the combustion chamber can be attributed to deficiencies of the injection holes manufacturing technology.
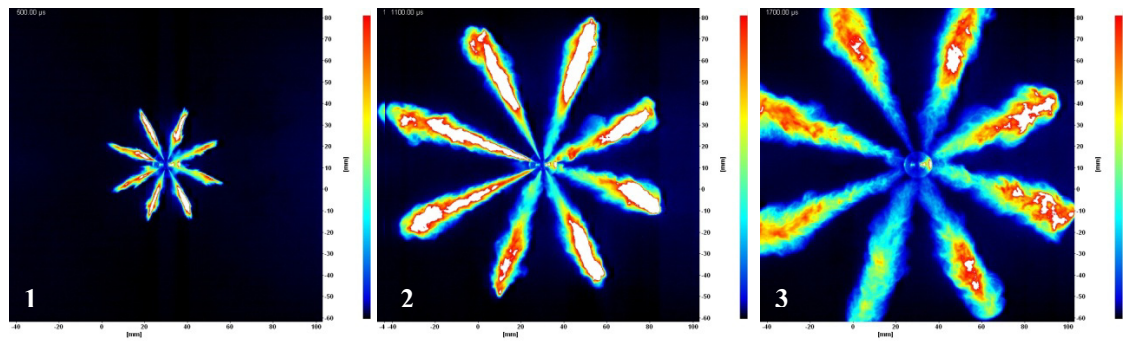

Figure 4: The step-by-step evolution of fuel streams in a high pressure chamber (rail pressure - $155 \mathrm{MPa}$; time of energizing - $400 \mu \mathrm{s}$ ).

The color-palettes for slides (fig. 4) show the level of intensity for fuel streams with the following boundaries: red color - maximal intensity; blue color - minimal value of intensity.

Control of the guiding precision interface was carried out according to the flow-rate of the leakage collected in a separate reservoir, and by the capacity consumed by the high-pressure pump. The condition of the guiding interface was found to be satisfactory, as the total leakage and capacity consumption to drive the high-pressure pump were comparable with the values shown when using traditional nozzles. 


\section{Results and discussion for future perfection of the nozzle's design}

The investigated nozzle design, which provides a longer service life at increasing rail pressure is a satisfactory solution, but without account of the processes, which take place in sealing precision interface of the nozzle. Decrease of the length and diameter of guiding precision interface of the nozzle with increased service-life, of course, leads to decreasing the deviation of the needle axe from the axe of the nozzle's body in the area of guiding precision interface, but it is not effective for decreasing the mentioned deviation for sealing interface. As a result, the decrease of the sealing ability, uncontrolled leakages and even subinjections, increase of the wear and change of the output parameters of the diesel engine are undesirable, though possible.

It should be noted that this problem comes very actual at application of transport dual (gas-diesel) fuel for convenient diesel engines with a gas-diesel operation cycle, because due to decreasing the mass-flow of the liquid diesel fuel, simultaneously, the cooling ability from diesel fuel for nozzle's components decreases as well.

The proposed design of the nozzle's tribocontacts with changed scheme of contact interaction (fig. 5) provides the division of the functions of nozzle's precision interfaces. There are two (top and bottom) cylindrical precision interfaces, which are shaped by the needle and the nozzle's body. The top cylindrical interface has mainly sealing and, partially, guiding function. The bottom precision interface of the nozzle has guiding function only, due to the features of design, presence of vertical channels for diesel fuel and absence of the sealing ability, but this design of the needle allows to achieve a more stable condition for the needle in course of diesel engine's operation cycle.

\section{Top cylindrical precision interface}

Bottom cylindrical precision interface

Sealing precision interface

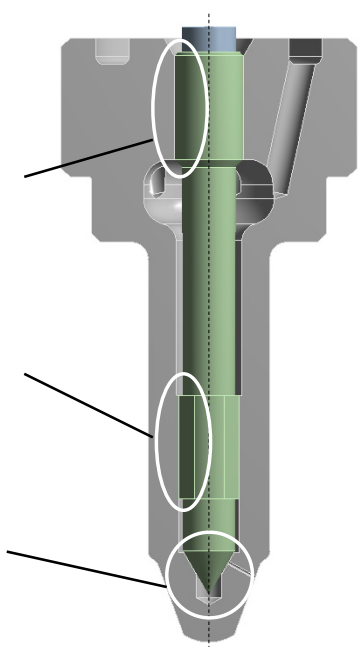

Figure 5: The proposed nozzle's design with two precision tribo-interfaces. 
This approach seems to be the most useful from the point of view of minimization of deviation of the needle axe from the axe of the nozzle's body in area of sealing precision interface of the nozzle, but contact parameters for top and bottom cylindrical interfaces still need more detailed study.

The existence of interdependence of the contact parameters for top and bottom cylindrical interfaces due to their location on the nozzle's needle is obvious and, subsequently, there is strong influence of the mentioned parameters on the situation in sealing precision interface. Additionally, they influence the efficiency of the diesel engine, toxicity of exhaust gases and durability of the nozzle. The existing problems of this type of interaction are to be studied especially for rail pressure much more than $155 \mathrm{MPa}$ (investigated values) and up to $280 \ldots 300 \mathrm{MPa}$.

\section{Dissemination of results}

Due to developing the radial force in the guiding precision interface, the research results which were achieved in course of nozzle's tests are applicable for most types of ICE-injectors. However, the proposed nozzle's design seems to be interesting for other types of industrial precision products, like high-pressure pumps, plungers controlling devices, high-precision bearings etc.

From the point of view of dissemination of the results, injection rate tests should be considered as corresponding only the investigated nozzle's design, but the idea of separating the functions for guiding (bottom) and guiding/sealing (top) precision interfaces with following studying the interface's properties, efficiency of application and ratio of inter-influencing seems to be quite transformative to other types of precision systems.

The problem of wear, inclinations, increasing of the montage-, thermal- and mechanical- deformations come to be more and more actual with increasing the operation-liquid pressure (in case of diesel engine's CR systems - rail pressure). With increasing the operation-pressure the precision systems need to be protected against non-controlled rising of the forces, which lead to increasing the wear and, subsequently, decreasing the service life.

Thus, the received results can be disseminated for other types of precision tribosystems, but the stated problem and technical solutions must be considered especially for each type of industrial precision products.

\section{Conclusions}

Analysis of parameters and characteristics of injection which are carried out with the injection rate analyzer and high pressure chamber as well as the perfection of the nozzle's design lead to the following conclusions.

1. The investigated experimental nozzle with a shortened nozzle body can be used in modern diesel injection systems (CR systems) at increased rail pressure 
up to $155 \mathrm{MPa}$, which is necessary for achieving the required economic and ecological environmental performance of the diesel engines;

2 . With the highest values of investigated rail pressures (155 $\mathrm{MPa})$ the relatively stable phases of the injection, regular distribution and similar penetration of fuel were observed. There are just slightly different intensities of fuel flows caused by the technology of producing the nozzle's injection holes;

3. Number, shape and size of the channels forming the injection holes of the nozzle should be evaluated together with the analysis of their production technology. Injection holes diameter $-0.2 \ldots 0.21 \mathrm{~mm}$ are suitable for stable operation of the injection at the rail pressures ranging up to $155 \mathrm{MPa}$. However, the following increase of the rail pressure will lead to necessary modification of the nozzle and, probably, to the following decreasing the diameters of the nozzle's injection holes.

\section{Outlook}

General directions of the following investigations should be focused on modification of the needle's and nozzle's body design and implementation of additional precision guiding interface for the bottom part of the needle according to the proposed nozzle's tribosystems design (fig. 5). These actions which should perfect the operation conditions for guiding and for sealing precision interfaces, needs additional investigations and seems to be very interesting and promising.

\section{Acknowledgements}

This work was funded by the Ministry of Education and Science of the Russian Federation (Moscow, Russia, project HM-3746) and DAAD - German Academic Exchange Service (Bonn, Germany, project A/14/72492, Ref. 325) and has been carried out within the Institute of "Internal Combustion Engines" of München Technical University (München, Germany) and financial supporting of the Ministry of Education and Science of the Russian Federation for the realization of applied research by lot number 2014-14-579-0109 with a unique identifier of applied scientific research (project) RFMEFI57714X0102. The investigations are performed by South Ural State University which is a recipient of subsidy, agreement № 14.577.21.0102.

\section{References}

[1] Robert Bosch GmbH Dieselmotor-Management, volume 3 - 2002. ISBN 3528-13873-4.

[2] Grosse-Löscher, H.; Haberland, H.: Schwarmintelligenz zur Optimierung von Einspritzdüsen. In: MTZ 71 (2010), Nr. 2, S. 80-85. 
[3] V.E. Lazarev, J. Wloka, G. Wachtmeister A Method for the Estimation of the Service Life of a Precision Guiding Interface "Needle - Nozzle Body" of a Common-Rail-Injector for High Rail Pressures/Proceedings of the JSAE/SAE International Conference - Powertrains, Fuels and Lubricants, 30 Aug.-2 Sept., 2011, Kyoto, Japan. Copyright (C) 2011 Society of Automotive Engineers of Japan, Inc.

[4] Pflaum, S \& Wachtmeister, G.: Dieselmotor im Grenzbereich, Proceedings of the ATZ-Conference Heavy Duty Engines, Bonn 2008, Germany.

[5] Peters A.: Das Common Rail-Einspritzsystem - Ein Potenzial für den Direktenspritz-Dieselmotor, 3. Stuttgarter Motorensymposium, 23-25 February 1999. 